\title{
Helicobacter pylori catalase
}

\author{
Stuart L. Hazell, ${ }^{1 *}$ Doyle J. Evans, $\mathrm{JR}^{2}$ and David Y. GrahaM ${ }^{2}$ \\ ${ }^{1}$ School of Microbiology, University of New South Wales, PO Box 1, Kensington, NSW 2033, Australia \\ ${ }^{2}$ Digestive Disease Section, Veterans' Affairs Medical Center and Baylor College of Medicine, Houston, Texas, USA
}

(Received 26 June 1990; revised 31 August 1990; accepted 11 September 1990)

\begin{abstract}
Helicobacter pylori is the major aetiological agent of gastroduodenitis in humans. Due to the potential importance of catalase in the growth and survival of Helicobacter pylori on the surface of inflamed mucosae, we have characterized catalase from $\mathrm{H}$. pylori as a prelude to further studies on the function of the enzyme in vivo. The catalase activity of $\boldsymbol{H}$. pylori was significantly affected by the presence of blood, serum or erythrocytes in the growth medium: the greatest activity was expressed when the bacterium was grown on medium containing serum. $H$. pylori catalase is a tetramer with a subunit $M_{\mathrm{r}}$ of 50000. The enzyme had a pI of 9.0-9.3, was active over a broad pH range and was stable at $56{ }^{\circ} \mathrm{C}$. It was non-competitively inhibited by sodium azide, and had no detectable peroxidase activity. The $K_{\mathrm{m}}$ for the purified catalase was measured as $43 \pm 3 \mathrm{mM}-\mathrm{H}_{2} \mathrm{O}_{2}$ and the $V$ as $60 \pm 3 \mathrm{mmol}$ $\mathrm{H}_{2} \mathrm{O}_{2}$ min $^{-1}(\mathrm{mg} \text { protein })^{-1}$. The native catalase has absorption maxima at $280 \mathrm{~nm}$ and $405 \mathrm{~nm}$ with further minor shoulders or peaks at $510 \mathrm{~nm}, 535 \mathrm{~nm}$ and $625 \mathrm{~nm}$, consistent with the presence of an iron-porphyrin prosthetic group.
\end{abstract}

\section{Introduction}

Catalase (EC 1.11.1.6) is an important enzyme for the protection of bacteria against the damaging effects of hydrogen peroxide. Although catalase activity does not always correlate with resistance to exogenous $\mathrm{H}_{2} \mathrm{O}_{2}$, this enzyme is important to some bacteria in resisting the effects of toxic oxygen species released during inflammatory processes, particularly those involving polymorphonuclear leucocytes (Schwartz et al., 1983; Beaman et al., 1985; Wilson \& Weaver, 1985).

Helicobacter (Campylobacter) pylori is the pathogen primarily responsible for gastroduodenitis in humans (Goodwin et al., 1986; Hazell et al., 1986a, b). In adults H. pylori gastritis begins with an acute imflammatory response (predominantly polymorphonuclear leucocytes) followed by infiltration with mononuclear cells. This results in the characteristic inflammatory lesion associated with $H$. pylori infection, acute on chronic gastritis (Morris \& Nicholson, 1987; Frommer et al., 1988) which persists despite the cellular and humoral response to the presence of the organism (Jones et al., 1984). The mechanisms whereby $H$. pylori is able to thrive in such an apparently hostile environment remain to be elucidated. Because of the potential role played by catalase in maintaining a stable environment for the growth of $H$. pylori in vivo, we have characterized the enzyme as a prelude to a better understanding of its role as a putative virulence factor of $H$. pylori. Part of this work was presented as a poster at the Vth International Campylobacter Workshop, Puerto Vallarta, Mexico, 1989.

\section{Methods}

Bacteria. Helicobacter pylori strains were isolated from gastric biopsies obtained from patients undergoing endoscopy at the Veterans' Affairs Medical Center, Houston, Texas. Strains were characterized as previously described (Hazell et al., 1986b). Campylobacter jejuni strains were obtained from the hospital microbiology department culture collection. H. pylori isolates were designated 8826 (laboratory-adapted isolate), 8801, 8802, 8803 and 8804 (fresh isolates).

Culture conditions. Cultures were incubated at $37{ }^{\circ} \mathrm{C}$ in an environment of $10 \%(\mathrm{v} / \mathrm{v}) \mathrm{CO}_{2}$ in air and $99 \%$ relative humidity. Unless otherwise specified, cultures were grown on $5-7 \%(v / v)$ horse blood agar. When testing for the effect of blood products on catalase activity H. pylori was grown on a semi-defined basal medium [Iso-Sensitest Agar (ISA), Oxoid] and ISA supplemented with either $5 \%$ citrated human blood (blood agar), $5 \%$ human serum (ISA/serum) or $5 \%$ human erythrocytes washed in Alsevier's solution (ISA/RBC) as previously described (Hazell et al., 1989). The blood or blood products were obtained fresh from a healthy $H$. pylori-negative volunteer.

Catalase extraction and chromatography. $H$. pylori cells were washed

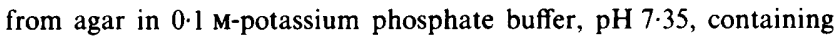
$0.005 \%$ merthiolate (Eli Lilly \& Co) (buffer A) and $1.0 \mu \mathrm{g} \mathrm{ml}^{-1}$ leupeptin (Boehringer) (buffer A-L). The cells were centrifuged at $17000 \mathrm{~g}$ for $8 \mathrm{~min}$, resuspended in buffer A-L and disrupted by three cycles through a French pressure cell. This extract was then centrifuged at $17000 \mathrm{~g}$ for $8 \mathrm{~min}$, and the supernatant was recovered and recentrifuged at $75000 \mathrm{~g}$ for $45 \mathrm{~min}$. In the case of isolate 8826 , due to 
the presence of excess insoluble material that interfered with the chromatography, the final supernatant was mixed 50:50 with Percoll (Pharmacia) and centrifuged at $39000 \mathrm{~g}$ for $20 \mathrm{~min}$. Insoluble material was discarded.

The final supernatant or the final supernatant in Percoll was applied to a K 26/100 gel filtration column of Sephacryl S-300 HR (Pharmacia) using buffer $\mathrm{A}$ as the liquid phase at a flow rate of $0.5 \mathrm{ml} \mathrm{min} \mathrm{m}^{-1}$ and eluted. The catalase-positive fractions were pooled and concentrated 10-fold (Amicon Centriprep 30 concentrator, W. R. Grace \& Co., Danvers, MA, USA). The concentrate was brought back to the original volume with deionized distilled water. The crude catalase was filtered ( $0.2 \mu \mathrm{m}$ pore size membrane), and then applied to a Domnick Hunter (now Millipore) MEMSEP 1000-CM ion-exchange capsule (Phenomenex, Rancho Palos Verdes, CA, USA) previously equilibrated with $1 / 10$ concentration buffer $A$. After washing to remove unbound proteins, the catalase was eluted with a linear gradient generated by $1 \mathrm{M}-\mathrm{KCl}$ in $1 / 10$ buffer $\mathrm{A}$. The catalase was then rechromatographed through the Sephacryl S-300 HR column. Merthiolate was removed by rapid dialysis against $0.1 \mathrm{M}$-phosphate-buffered saline (PBS), pH 7.35, using the Amicon Centriprep 30 concentrator. The merthiolate-free catalase was filter-sterilized $(0.2 \mu \mathrm{m}$ pore size membrane $)$ and stored in the dark at $4{ }^{\circ} \mathrm{C}$.

Determination of catalase activity. Qualitative catalase activity was tested by adding $50 \mu$ l of the test material to $100 \mu \mathrm{l}$ of a $3 \%(\mathrm{v} / \mathrm{v}) \mathrm{H}_{2} \mathrm{O}_{2}$ solution in a microtitre plate and watching for the rapid evolution of oxygen.

Quantitative catalase activity was determined after the method of Beers \& Sizer (1952). Solutions of $10-200 \mu \mathrm{l}$ of $30 \%(\mathrm{v} / \mathrm{v}) \mathrm{H}_{2} \mathrm{O}_{2}$ in $50 \mathrm{ml}$ $0.1 \mathrm{M}-\mathrm{PBS}, \mathrm{pH} 7.35$ at $25^{\circ} \mathrm{C}$ were prepared and the concentration of each solution determined spectrophotometrically using a molar absorption coefficient of $43.481 \mathrm{~mol}^{-1} \mathrm{~cm}^{-1}$ at $240 \mathrm{~nm}$. Reaction kinetics of isolated catalase were determined by mixing $100 \mu$ l enzyme in $2.9 \mathrm{ml} \mathrm{H}_{2} \mathrm{O}_{2}$ solutions with the initial reaction rates recorded using a programmable printer (Spectrophotometer 252, Gilford Instrument Laboratories). All assays were repeated to give 12 rate determinations for the first minute of reaction and these were recorded as the rate of decomposition of $\mathrm{H}_{2} \mathrm{O}_{2} \mathrm{~min}^{-1}$ (mg protein) ${ }^{-1} . K_{\mathrm{m}}$ and $V$ values were determined by Lineweaver-Burk plots. The line of best fit and regression analysis was computed using Microstat (Ecosoft Inc., Indianapolis, IN, USA).

Comparisons of the catalase activities of whole bacteria were made using $100 \mu \mathrm{l}$ of a cell suspension consisting of bacteria washed in icecold PBS and adjusted to $\mathrm{OD}_{600}=1 \cdot 0$. A standardized solution of $\mathrm{H}_{2} \mathrm{O}_{2}$ in PBS $\left(A_{240}=0.55\right)$ at $25^{\circ} \mathrm{C}$ was used for these assays with the reaction rate determined as above. Data from experiments using whole cells were compared using analysis of variance.

Characterization of catalase. The $M_{\mathrm{r}}$ of the native catalase was determined by gel filtration through fresh Sephacryl S-300 HR in 0.1 Mpotassium phosphate buffer, $\mathrm{pH} 7 \cdot 35$, without merthiolate - which can interact with some proteins in the column - as compared to gel filtration $\boldsymbol{M}_{\mathrm{r}}$ markers (Sigma). The subunit $\boldsymbol{M}_{\mathrm{r}}$ was determined by SDSPAGE under fully denatured and reduced conditions using SDS $M_{\mathrm{r}}$ markers (Bio-Rad). The isoelectric point was measured on a PhastGel IEF polyacrylamide gel (Pharmacia). Proteins were stained with Coomassie brilliant blue $\mathbf{R}$ dissolved in methanol/acetic acid.

Peroxidase activity was assayed spectrophotometrically using 4chloro-1-naphthol $/ \mathrm{H}_{2} \mathrm{O}_{2}$, dissolved in $0.05 \mathrm{M}$ - Tris $/ \mathrm{HCl}$, pH 7.5, containing $0 \cdot 2 \mathrm{M}-\mathrm{NaCl}$, as substrate. Purified enzyme $(100 \mu \mathrm{l})$ was mixed with $100 \mu \mathrm{l}$ of substrate solution in the well of a microtitre plate and the plate, with the inclusion of appropriate controls, was incubated for $30 \mathrm{~min}$ in the dark at room temperature. Colour development was measured on a Titertek Multiskan instrument (Flow Laboratories).

The $\mathrm{pH}$ optimum of $H$. pylori catalase was tested in $0.1 \mathrm{M}$-potassium phosphate over a $\mathrm{pH}$ range of 5-25-8.95. Heat lability of $\boldsymbol{H}$. pylori catalase in $0 \cdot 1 \mathrm{M}-\mathrm{PBS}, \mathrm{pH} 7.35$, was tested by heating the enzyme in a water bath at $56^{\circ} \mathrm{C}$ for $60 \mathrm{~min}$. Aliquots were removed at $10 \mathrm{~min}$ intervals and their catalase activity measured quantitatively. The effect of sodium azide on catalase kinetics was tested at a concentration of $50 \mathrm{nM}$-sodium azide in the presence of $0.25 \mathrm{ng}$ catalase. The reaction rate was determined as outlined above. Reversibility of azide inhibition was tested after dialysis of azide-treated catalase against $0.1 \mathrm{M}$-PBS, pH 7.35 (three changes of buffer over $18 \mathrm{~h}$ at $4^{\circ} \mathrm{C}$ ). The spectrophotometric profile of the catalase was determined by scanning both the native protein and enzyme treated with $\mathrm{K}_{3} \mathrm{Fe}(\mathrm{CN})_{6} / \mathrm{KCN}$ (Tentori \& Salvati, 1981 ) in the range $260-680 \mathrm{~nm}$.

Protein determination. Protein estimations were made by either the bicinchoninic acid (BCA) or the microBCA protein assay systems (Pierce Chemical Co.). Bovine serum albumin was the protein standard.

\section{Results}

Effect of blood and blood products on catalase expression by $H$. pylori

The whole-cell catalase activity of $H$. pylori isolate 8826 grown on ISA, blood agar, ISA/serum and ISA/RBC over $96 \mathrm{~h}$ demonstrated that the length of incubation and the type of blood product in the medium had a significant effect $(P<0.001)$ on the catalase activity (Fig. 1). This

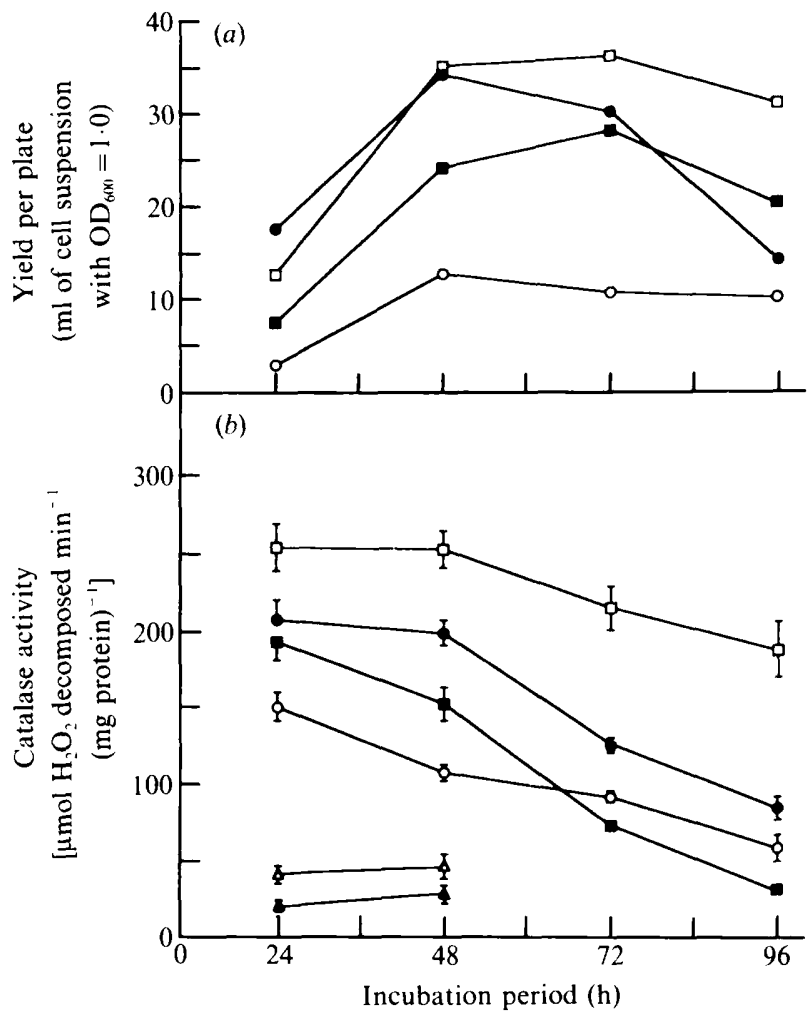

Fig. 1. Effect of incubation period and medium supplements on $(a)$ the yield of cells and $(b)$ the expression of catalase by whole cells of $H$. pylori strain 8826 when grown on basal medium (ISA) $(O)$ and basal medium containing human serum (ISA/serum) ( $\square$ ), blood (blood agar) (๑) or erythrocytes (ISA/RBC) (四). Catalase activity is also shown for two strains of $C$. jejuni, $1186(\triangle)$ and $1284(\Delta)$, grown on blood agar. The results in $(b)$ are plotted as means $\pm 95 \%$ confidence intervals. 
medium effect was also apparent with four other isolates (8801, 8802, 8803 and 8804) as determined using whole cells following $3 \mathrm{~d}$ incubation (Fig. 2). The whole-cell catalase activity of two strains of $C$. jejuni tested concurrently was about five times less active than $H$. pylori $(P<0.001)$ at the same specified $\mathrm{H}_{2} \mathrm{O}_{2}$ concentration (Fig. 1).

\section{Characterization of catalase}

$H$. pylori catalase was purified from two isolates $(8826$ and 8801) to the order of 65 -fold. The catalase from both isolates had identical properties; representative data from isolate 8826 are given below. The native catalase had an apparent $M_{\mathrm{r}}$ of $190000-200000$ as determined by gel filtration, whereas the reduced denatured enzyme

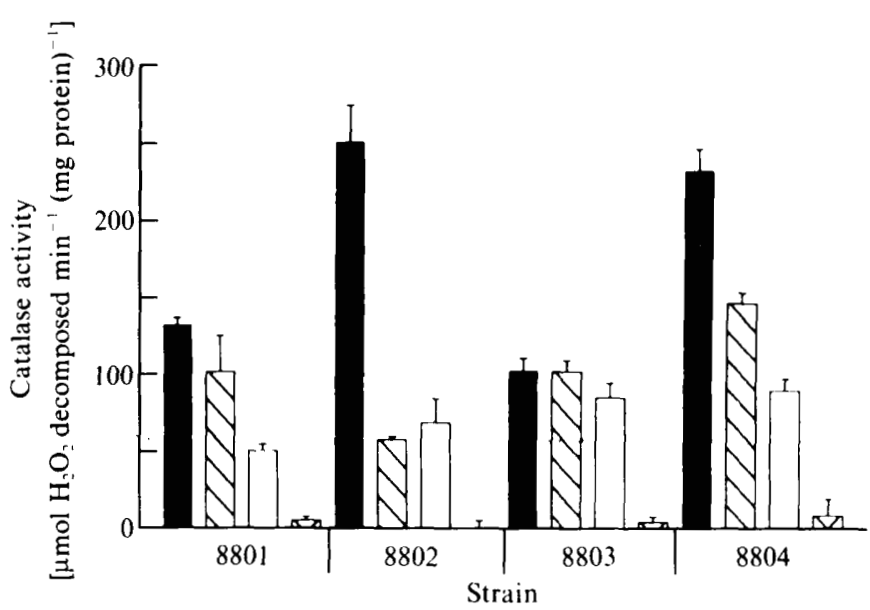

Fig. 2. Effect of medium supplements on whole-cell catalase expression by fresh isolates of $H$. pylori, 8801, 8802, 8803 and 8804 , when grown on the basal medium (ISA) ( and basal medium containing human serum (ISA/serum) ( $\mathbf{W}$ ), blood (blood agar) (बII) or erythrocytes (ISA/RBC) ( $\square)$. Cultures were incubated for $3 \mathrm{~d}$. The results are means $\pm 95 \%$ confidence intervals.

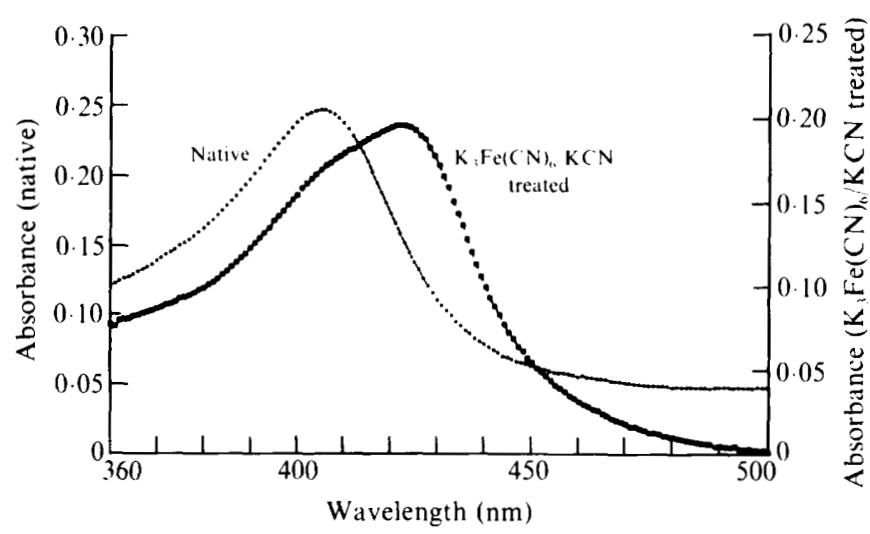

Fig. 3. Shift in the absorption spectrum of the native $H$. pylori catalase following treatment with $\mathrm{K}_{3} \mathrm{Fe}(\mathrm{CN})_{6} / \mathrm{KCN}$. had an apparent $M_{\mathrm{r}}$ of the order of 50000 . The isoelectric point was in the range $9 \cdot 0-9 \cdot 3$. The $H$. pylori catalase was active over a broad $\mathrm{pH}$ range, showing no significant difference in activity between $\mathrm{pH} 6.5$ and 8.95 . It was stable at $56^{\circ} \mathrm{C}$ for $1 \mathrm{~h}$ and was reversibly inhibited by sodium azide. Kinetic data were consistent with this inhibition being non-competitive. No peroxidase activity was detected.

The kinetic properties of the catalase from $H$. pylori were determined; the $K_{\mathrm{m}}$ was measured as $43 \pm 3 \mathrm{~mm}$ $\mathrm{H}_{2} \mathrm{O}_{2}$ and the $V$ as $60 \pm 3 \mathrm{mmol} \mathrm{H}_{2} \mathrm{O}_{2}$ decomposed $\min ^{-1}$ (mg protein) $)^{-1}$.

The native catalase has absorption maxima at $280 \mathrm{~nm}$ and $405 \mathrm{~nm}$ (Soret band) and further minor shoulders or peaks at $510 \mathrm{~nm}, 535 \mathrm{~nm}$ and $625 \mathrm{~nm}$, and a $405 / 280$ ratio of 0.65 . Treatment with $\mathrm{K}_{3} \mathrm{Fe}(\mathrm{CN})_{6} / \mathrm{KCN}$ produced a spectral shift of the $405 \mathrm{~nm}$ peak to $422 \mathrm{~nm}$ (Fig. 3).

\section{Discussion}

Catalase is a ubiquitous enzyme found in eukaryotic and most prokaryotic organisms. The native $H$. pylori catalase appears to be a tetramer $\left(M_{\mathrm{r}} 200000\right)$ and the spectral analysis reported here is consistent with the presence of an iron-porphyrin prosthetic group (Hochman \& Shemesh, 1987). The enzyme is soluble and may be distributed throughout the cytosol and in the periplasmic space (unpublished results). Whether the catalase is loosely associated with specific membrane proteins remains to be determined.

$H$. pylori catalase was reversibly and non-competitively inhibited by sodium azide. Azide combines reversibly with iron-porphyrin prosthetic groups and causes a reduction of the iron to the ferrous state (Keilin \& Hartree, 1945; Lamberg \& Foulkes, 1948). Azide and cyanide may appear as non-competitive catalase inhibitors; however, under conditions of high substrate concentration they may act as competitive inhibitors (Ogura, 1955). The enzyme was heat stable and had a broad $\mathrm{pH}$ activity similar to that seen with Klebsiella pneumoniae (KpT) and Escherichia coli (HPII), the latter having two distinct activity peaks at $\mathrm{pH} 6.8$ and 10.5 (Meir \& Yagil, 1985; Goldberg \& Hochman, 1989). Unlike the E. coli catalases (HPII and HPI; Meir \& Yagil, 1985), no concomitant peroxidase activity was detected for $H$. pylori catalase. Heat stability is a property shared by the non-peroxidase catalases (i.e. the 'typical' catalases) and the characteristics of $H$. pylori catalase are consistent with the enzyme being a 'typical' catalase.

The isoelectric point of the $H$. pylori catalase $(9 \cdot 0-9 \cdot 3)$ appears unique. The isoelectric point of catalase usually occurs at an acid pH (e.g. Rhodopseudomonas capsulata, 
4.5, and Pseudomonas pyrrocinia, 5.0; Weisner et al., 1985; Hochman \& Shemesh, 1987). This characteristic of the enzyme may represent an adaptation to a unique environment.

In media supplemented with different blood products, there was a fall in the catalase activity of $H$. pylori as the relative concentration of erythrocytes increased and that of serum decreased. This is consistent with either a serum factor(s) stimulating catalase activity and/or the presence of haem-containing proteins, released from erythrocytes by the action of $\boldsymbol{H}$. pylori (Wetherall \& Johnson, 1989), suppressing the synthesis of catalase. Suppression of synthesis of porphyrins by haem groups has been demonstrated in mature mammalian cells; and in rodents, liver catalase activity increases subsequent to serum injection (Weil-Malherbe \& Schade, 1948; Woods, 1974). In E. coli, the expression of catalase activity is subject to catabolite repression in the presence of glucose (Meir \& Yagil, 1990). Whether glucose, or other compounds, can repress the catalase activity of $H$. pylori, which is non-glycolytic, remains to be determined. Also, unlike E.coli (Meir \& Yagil, 1990), the expression of catalase in $H$. pylori was not enhanced by the cells entering stationary phase, as the highest activity occurred in young cultures. Twoor possibly three catalases have been identified in E. coli (Meir \& Yagil, 1985; Peyru $\&$ Fraenkel, 1968). In the studies reported here we have identified one isomer of catalase. Whether other isomers of catalase can be induced in $H$. pylori under conditions such as oxidative stress remains to be determined.

The catalase activity of $\boldsymbol{H}$. pylori was significantly greater than that of the related bacterium $C$. jejuni. $H$. pylori is a major aetiological agent of human acute on chronic gastritis and a pronounced catalase activity may aid the survival of the bacterium in vivo. Beaman et al. (1985) noted that resistance of Nocardia asteroides to the microbicidal activity of polymorphonuclear leucocytes, which can release $\mathrm{H}_{2} \mathrm{O}_{2}$ both intra- and extracellularly (Clifford \& Repine, 1982), was mediated by both superoxide dismutase and catalase. However, the presence or absence of catalase does not render absolutely a bacterium more or less susceptible to the lethal effects of $\mathrm{H}_{2} \mathrm{O}_{2}$, as susceptibility to $\mathrm{H}_{2} \mathrm{O}_{2}$ can also be dependent upon the sensitivity of cellular components to oxidative damage (Schwartz et al., 1983; Wilson \& Weaver, 1985). We (Hazell et al., 1989; Hazell \& Graham, 1990) have previously demonstrated that bovine liver catalase can aid the growth of $H$. pylori in vitro, this being due, in part, to the prevention of formation of toxic peroxidated fatty acids. These data would indicate that $H$. pylori is at least indirectly sensitive to oxidative damage. Whereas endogenous catalase of $H$. pylori does not appear to play a role in conditioning the external environment, it may be critical at the cellular level.
The $K_{\mathrm{m}}$ for $H$. pylori catalase was 3-10 times higher than that recorded for most other bacteria, but about one-third that of heat-stable mycobacterial catalase. Also, the enzyme was stable at concentrations of $\mathrm{H}_{2} \mathrm{O}_{2}$ known to inhibit other bacterial catalases, a property shared with several species of the genus Mycobacteria (Wayne \& Diaz, 1982; Meir \& Yagil, 1985; Allgood \& Perry, 1986; Hochman \& Shemesh, 1987;Goldberg \& Hochman, 1989). These properties could relate to the adaptation of the mycobacterial and $H$. pylori enzymes to an environment rich in toxic oxygen species.

This paper provides fundamental information on the nature and activity of $H$. pylori catalase and is a prelude to further studies that will determine if this enzyme is important in enabling $H$. pylori to survive on the surface of inflamed gastroduodenal mucosae.

Stuart Hazell is a C. J. Martin Fellow supported by the National Health and Medical Research Council of Australia. This work was supported in part by the Veterans' Affairs, in part by grant DK-39919 from the National Institute of Digestive and Kidney Diseases and by the generous support of Hilda Schwartz. The authors would like to thank Drs Elliot Alpert and Mike Edwards for their constructive comments.

\section{References}

Allgood, G. S. \& Perry, J. J. (1986). Characterization of a manganese-containing catalase from the obligate thermophile Thermoleophilum album. Journal of Bacteriology 168, 563-567.

Beaman, B. L., Black, C. M., Doughty, F. \& Beaman, L. (1985). Role of superoxide dismutase and catalase as determinants of pathogenicity of Nocardia asteroides: importance in resistance to microbicidal activity of human polymorphonuclear neutrophils. Infection and Immunity 47, 135-141.

BeERs, R. F., JR \& SizER, I. W. (1952). A spectrophotometric method for measuring the breakdown of hydrogen peroxide by catalase. Journal of Biological Chemistry 195, 133-140.

Clifford, D. P. \& Repine, J. E. (1982). Hydrogen peroxide mediated killing of bacteria. Molecular and Cellular Biochemistry 49, 143-149.

Frommer, D. J., Carrick, J., Lee, A \& Hazell, S. L. (1988). Acute presentation of Campylobacter pylori gastritis. American Journal of Gastroenterology 83, 1168-1171.

GoldBerg, I. \& Hochman, A. (1989). Three different types of catalase in Klebsiella pneumoniae. Archives of Biochemistry and Biophysics 268, 124-128.

Goodwin, C. S., Armstrong, J. A. \& Marshall, B. J. (1986). Campylobacter pyloridis, gastritis, and peptic ulceration. Journal of Clinical Pathology 39, 353-365.

Hazell, S. L. \& Graham, D. Y. (1990). Unsaturated fatty acids and viability of Helicobacter (Campylobacter) pylori. Journal of Clinical Microbiology 28, 1060-1061.

Hazell, S. L., Hennessy, W. B., Borody, T. J., Carrick, J., RAlston, M., BRADY, L. \& LEE, A. (1986a). Campylobacter pyloridis gastritis II: distribution of bacteria and associated inflammation in the gastroduodenal environment. American Journal of Gastroenterology 82, 297-301.

Hazell, S. L., Lee, A., Brady, L. \& Hennessy, W. (1986b). Campylobacter pyloridis and gastritis: association with intercellular spaces and adaption to an environment of mucus as important factors in colonization of the gastric epithelium. Journal of Infectious Diseases 153, 658-663. 
Hazell, S. L., Markesich, D. C., Evans, D. J., JR, Evans, D. G. \& GrahaM, D. Y. (1989). Influence of media supplements on the growth and survival of Campylobacter pylori. European Journal of Clinical Microbiology and Infectious Disease 8, 597-602.

Hochman, A. \& Shemesh, A. (1987). Purification and characterization of a catalase-peroxidase from the photosynthetic bacterium Rhodopseudomonas capsulata. Journal of Biological Chemistry 262, $6871-6876$.

JoNES, D. M., LASSELls, A. M. \& ELDRIDGE, J. (1984). Campylobacterlike organisms on the gastric mucosa: culture, histological and serological studies. Journal of Clinical Pathology 37, 1002-1006.

KeILIN, D. \& Hartree, E. F. (1945). Properties of azide-catalase. Biochemical Journal 39, 148-157.

LAMBERG, R. \& FoulKes, E. C. (1948). Reaction between catalase and hydrogen peroxide. Nature, London 161, 131-132.

MEIR, E. \& YAGIL, E. (1985). Further characterization of the two catalases in Escherichia coli. Current Microbiology 12, 315-320.

MEIR, E. \& YAGIL, E. (1990). Regulation of Escherichia coli catalase by anaerobiosis and catabolite repression. Current Microbiology 20 , 139-143.

MorRIs, A. \& Nicholson, G. (1987). Ingestion of Campylobacter pyloridis causes gastritis and raised fasting gastric $\mathrm{pH}$. American Journal of Gastroenterology 82, 192-199.

OGURA, Y. (1955). Catalase activity at high concentrations of hydrogen peroxide. Archives of Biochemistry and Biophysics 57, 288-300.
Peyru, G. \& Fraenkel, D. G. (1968). Genetic mapping of loci for glucose-6-phosphate dehydrogenase, gluconate-6-phosphate dehydrogenase, and gluconate-6-phosphate dehydrase in Escherichia coli. Journal of Bacteriology 95, 1272-1278.

Schwartz, C. E., Krall, J., Norton, L., McKay, K., Kay, D. \& LYNCH, R. E. (1983). Catalase and superoxide dismutase in Escherichia coli. Journal of Biological Chemistry 258, 6277-6281.

Tentori, L. \& Salvati, A. M. (1981). Hemoglobinometry in human blood. Methods in Enzymology 76, 707-731.

WaYNe, L. G. \& Diaz, G. A. (1982). Serological, taxonomic, and kinetic studies of the $\mathrm{T}$ and $\mathrm{M}$ classes of mycobacterial catalase. International Journal of Systematic Bacteriology 32, 296-304.

Weil-MaLherbe, H. \& SCHADE, R. (1948). Studies on the liver catalase of normal and cancerous rats. Biochemical Journal 43, 118-125.

Weisner, W., van Pee, K. H. \& Lingens, F. (1985). Purification and properties of bromoperoxidase from Pseudomonas pyrrocinia. Biological Chemistry Hoppe-Seyler 366, 1085-1091.

Wetherall, B. L. \& JohNSON, A. M. (1989). Haemolytic activity of Campylobacter pylori. European Journal of Clinical Microbiology and Infectious Disease 8, 706-710.

WILSON, C. B. \& WeAVER, W. M. (1985). Comparative susceptibility of group B streptococci and Staphylococcus aureus to killing by oxygen metabolites. Journal of Infectious Diseases 152, 323-329.

Woods, J. S. (1974). Studies on the role of heme in the regulation of delta-aminolevulinic acid synthetase during fetal hepatic development. Molecular Pharmacology 10, 389-397. 